\title{
Exposure to Cocaine Dynamically Regulates the Intrinsic Membrane Excitability of Nucleus Accumbens Neurons
}

\author{
Ping Mu, ${ }^{1}$ Jason T. Moyer, ${ }^{2,3}$ Masago Ishikawa, ${ }^{1}$ Yonghong Zhang, ${ }^{1}$ Jaak Panksepp, ${ }^{1}$ Barbara A. Sorg, ${ }^{1}$ \\ Oliver M. Schlüter, ${ }^{4}$ and Yan Dong ${ }^{1}$ \\ ${ }^{1}$ Program in Neuroscience, Washington State University, Pullman, Washington 99164-6520, ${ }^{2}$ Department of Bioengineering, University of Pennsylvania, \\ Philadelphia, Pennsylvania 19104, ${ }^{3} \mathrm{FHC}$ Inc., Bowdoin, Maine 04287, and ${ }^{4}$ Department of Molecular Neurobiology, European Neuroscience Institute, 37077 \\ Göttingen, Germany
}

Drug-induced malfunction of nucleus accumbens (NAc) neurons underlies a key pathophysiology of drug addiction. Drug-induced changes in intrinsic membrane excitability of NAc neurons are thought to be critical for producing behavioral alterations. Previous studies demonstrate that, after short-term $(2 \mathrm{~d})$ or long-term $(21 \mathrm{~d})$ withdrawal from noncontingent cocaine injection, the intrinsic membrane excitability of NAc shell (NAcSh) neurons is decreased, and decreased membrane excitability of NAcSh neurons increases the acute locomotor response to cocaine. However, animals exhibit distinct cellular and behavioral alterations at different stages of cocaine exposure, suggesting that the decreased membrane excitability of NAc neurons may not be a persistent change. Here, we demonstrate that the membrane excitability of NAcSh neurons is differentially regulated depending on whether cocaine is administered contingently or noncontingently. Specifically, the membrane excitability of NAcSh medium spiny neurons (MSNs) was decreased at $2 \mathrm{~d}$ after withdrawal from either $5 \mathrm{~d}$ intraperitoneal injections $(15 \mathrm{mg} / \mathrm{kg}$ ) or cocaine self-administration (SA). At $21 \mathrm{~d}$ of withdrawal, the membrane excitability of NAcSh MSNs, which remained low in intraperitoneally pretreated rats, returned to a normal level in SA-pretreated rats. Furthermore, after a reexposure to cocaine after long-term withdrawal, the membrane excitability of NAcSh MSNs instantly returned to a normal level in intraperitoneally pretreated rats. Conversely, in SA-pretreated rats, the reexposure elevated the membrane excitability of NAcSh MSMs beyond the normal level. These results suggest that the dynamic alterations in membrane excitability of NAcSh MSNs, together with the dynamic changes in synaptic input, contribute differentially to the behavioral consequences of contingent and noncontingent cocaine administration.

\section{Introduction}

Functional alterations of the nucleus accumbens (NAc) by exposure to drugs of abuse contribute to a variety of addiction-related behaviors (Hyman et al., 2006). The functional output of a neuron, by definition, is the action potential (Hille, 2001). For NAc medium spiny neurons (MSNs), two key electrophysiological parameters determining the rate of action potentials are the excitatory synaptic input, which depolarizes the membrane toward the threshold of action potential, and the intrinsic membrane excitability, which determines whether and how many action potentials are fired during membrane depolarization. Thus, the functional output of NAc MSNs at a given moment is primarily determined by the integration of synaptic inputs and membrane excitability (Wilson and Groves, 1981).

To understand the impact of cocaine exposure on the functional output of NAc MSNs, extensive efforts have been directed

Received Aug. 12, 2009; revised Jan. 24, 2010; accepted Jan. 28, 2010.

This research was supported in part by State of Washington Initiative Measure 171, National Institutes of Health Grant DA023206 (Y.D.), the Hope Foundation for Depression Research (Y.D., J.P.), the Humboldt Foundation (Y.D.), and European Commission Coordination Action Network of European Neuroscience Institutes Contract LSHM-CT2005-19063 (0.M.S.). Cocaine was supplied by the Drug Supply Program of the National Institute on Drug Abuse. We thank Drs. Marina Wolf and Yanhua Huang for suggestions on this manuscript.

Correspondence should be addressed to Yan Dong, Wegner 205, P.0. Box 646520, Washington State University, Pullman, WA 99164-6520. E-mail:yan_dong@wsu.edu.

DOI:10.1523/JNEUROSCI.4063-09.2010

Copyright $\odot 2010$ the authors $\quad 0270-6474 / 10 / 303689-11 \$ 15.00 / 0$ toward elucidating cocaine-induced alterations in excitatory synapses using both noncontingent and contingent administration procedures. For example, surface or synaptic AMPA receptors (AMPARs) are increased in NAc MSNs after long-term (14-21 d) withdrawal $(\mathrm{w} / \mathrm{d})$ from either repeated intraperitoneal injections or intravenous self-administration (SA) of cocaine (Boudreau and Wolf, 2005; Kourrich et al., 2007; Conrad et al., 2008; Boudreau et al., 2009; Ferrario et al., 2010). Furthermore, the excitatory synaptic strength is decreased by a reexposure to cocaine after long-term withdrawal from repeated intraperitoneal injections of cocaine (Boudreau et al., 2007; Kourrich et al., 2007). Conversely, understanding of the impact of cocaine exposure on the membrane excitability of NAc MSNs is primarily derived from procedures using intraperitoneal injection of cocaine. A number of previous studies have shown that NAc shell (NAcSh) MSNs exhibit decreases in sodium and calcium conductances (Zhang et al., 1998, 2002), an increase in potassium conductance (Hu et al., 2004) after short-term withdrawal from repeated injections, and a decrease in evoked action potential firing after either a short- or long-term withdrawal (Henry and White, 1992; Dong et al., 2006; Ishikawa et al., 2009; Kourrich and Thomas, 2009). These changes consistently suggest that withdrawal from intraperitoneal injections of cocaine decreases the membrane excitability of NAcSh MSNs (White and Kalivas, 1998). However, it remains unclear how the intrinsic membrane excitability of NAcSh MSNs 

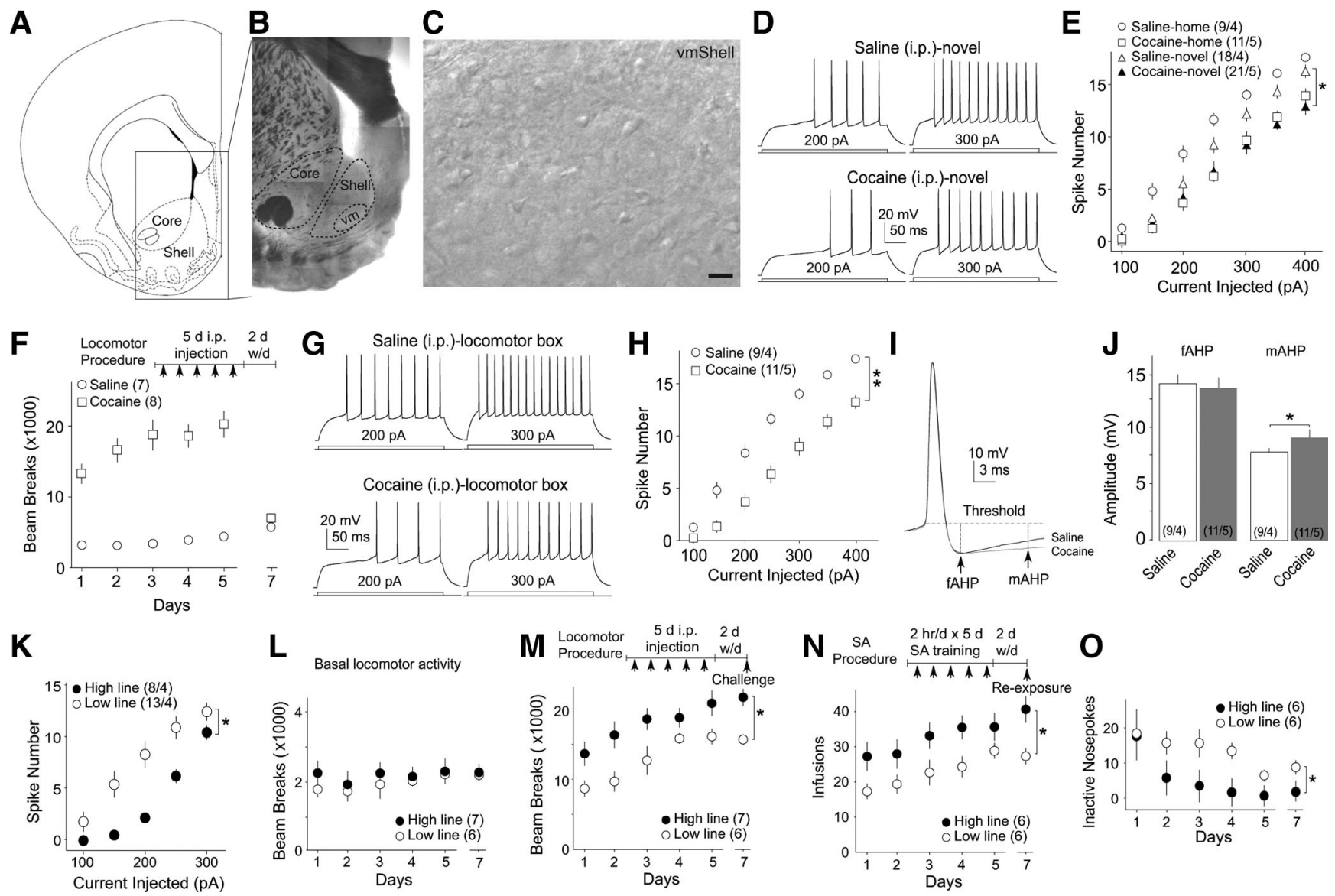

$\mathbf{L}$

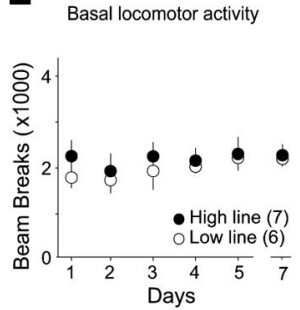

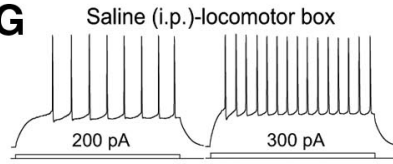

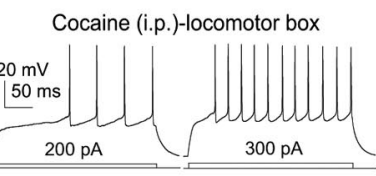

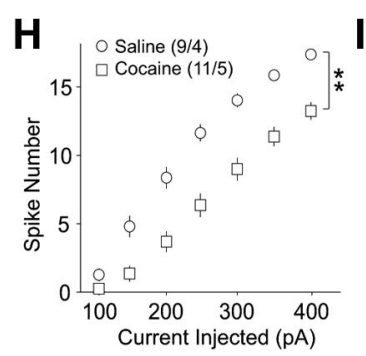

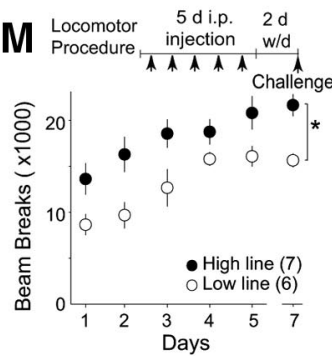

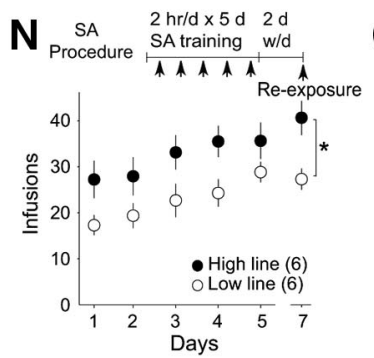


Figure 1. The intrinsic membrane excitability of NAcSh MSNs was decreased after $2 \mathrm{~d}$ withdrawal from $5 \mathrm{~d}$ intraperitoneal cocaine injections either within the home cages or in a novel environment. $\boldsymbol{A}, \mathrm{A}$ diagram showing the NAc shell and core. $\boldsymbol{B}$, An example brain slice at a low magnification (through the $4 \times$ objective) in which the dashed circles indicate the operationally defined core and shell regions as well as the ventral-medial region (vm) of the shell. $\boldsymbol{C}$, Example image at a high magnification (40X) showing MSNs within the ventral-medial regions of the shell of the NAc. Scale bar, $20 \mu \mathrm{m}$. Images in $\boldsymbol{B}$ and $\boldsymbol{C}$ were taken from the fresh tissue through the same microscope-imaging system used for identifying and recording NAcSh MSNs throughout the present study. D, Examples showing action potentials elicited by 200 and 300 pA current steps in two example NAcSh MSNs from rats receiving novelty-paired injections of saline and cocaine, respectively. $\boldsymbol{E}$, Summarized data showing that $2 \mathrm{~d}$ withdrawal from repeated intraperitoneal injections of cocaine, either within the home cages or in the novel environment, decreased the intrinsic membrane excitability of NAcSh MSNs. $\boldsymbol{F}$, Summarized data showing that rats receiving a $5 \mathrm{~d}$ procedure of intraperitoneal cocaine injection (diagrammed in the inset) exhibited sensitized locomotor responses. On day 7 ( $2 \mathrm{~d}$ withdrawal), the spontaneous locomotor activity was similar in both groups of rats. $\boldsymbol{G}$, Examples showing evoked action potentials in two NACSh MSNs from a saline-pretreated and a cocaine-pretreated rat in $\boldsymbol{F}$. $\boldsymbol{H}$, Summarized data showing that $2 \mathrm{~d}$ withdrawal from the locomotor sensitization procedure significantly decreased the membrane excitability of NAcSh MSNs. $I$, The averaged AHPs from all recorded MSNs from saline- and cocaine-pretreated rats. J, Summarized data showing that the mAHP, but not fAHP, was increased in cocaine-pretreated rats. $\boldsymbol{K}$ - $\boldsymbol{M}$, Summarized data showing that, between the two breeding lines of Long-Evans rats (high and low lines), the high line rats exhibited lower membrane excitability in NAcSh MSNs $(\boldsymbol{K})$ and higher cocaine-induced locomotor response ( $\boldsymbol{M}$ ), whereas the basal locomotor activity was similar in these two lines of rats ( $\boldsymbol{L})$. $\boldsymbol{N}$, Summarized data showing differential acquisition of cocaine $S A$ between high line and low line rats. $\mathbf{0}$, Summarized data showing that high line and low line rats exhibited different numbers of inactive nose pokes during the acquisition of cocaine $S A$. ${ }^{*} p<0.05$; ${ }^{* *} p<0.01$.

is regulated by contingent cocaine administration. The present study attempts to address this issue by comparing the evoked action potential firing of NAcSh MSNs between rats receiving two widely used cocaine procedures, the intraperitoneal injection of cocaine that triggers locomotor sensitization and selfadministration of cocaine via intravenous infusion. Our results show that the membrane excitability of NAcSh MSNs was dynamically and differentially regulated by the two procedures and by different withdrawal times. These results, together with previous results describing cocaine-induced synaptic and membrane alterations, help assess the overall functional output of NAcSh MSNs after different cocaine procedures.

\section{Materials and Methods}

Animal use. Male Sprague Dawley rats were used for all studies except the high positive affect line and low positive affect line rats (Burgdorf et al., 2005), which were bred from the Long-Evans line (Fig. $1 \mathrm{~K}-\mathrm{O}$ ). Rats with an age of 22-24 d were allowed to acclimate to their home cages for 5-7 d and then received cocaine administration. Thus, rats started receiving either intraperitoneal injection or SA of cocaine at $\sim 1$ month old. We chose to use relatively young rats because younger animals appear to exhibit faster acquisition of cocaine-elicited behaviors (Perry et al., 2007) and higher magnitudes of cellular alterations (Huang et al., 2009; Ishikawa et al., 2009). In a subset of experiments (Fig. $1 \mathrm{~K}-\mathrm{O}$ ), the high line and low line Long-Evans rats were used to explore the potential behavioral correlates of cocaine-induced decrease in membrane excitability of NAcSh MSNs. High and low line rats exhibit high and low levels of spontaneous ultrasonic vocalization at $\sim 55 \mathrm{kHz}$, respectively (Burgdorf et al., 2005). In rodents, vocalization at this specific frequency has been hypothesized as an expressive measure of the positive emotional/ motivational state (Panksepp and Burgdorf, 2003). Our previous study demonstrates that the high line rats exhibited a higher magnitude of cocaine-induced locomotor sensitization than low line rats ( $\mathrm{Mu}$ et al., 2009). Given the correlation between cocaine-induced locomotor response and the membrane excitability of NAcSh MSNs (Dong et al., 2006), we compared the membrane excitability of NAcSh MSNs between high and low lines of rats in a set of experiments (Fig. $1 \mathrm{~K}-\mathrm{O}$ ). 
Intraperitoneal injection of cocaine. We used a $5 \mathrm{~d}$ procedure of repeated cocaine administration, which was similar to previous studies (Dong et al., 2005; Ishikawa et al., 2009). Briefly, rats received one intraperitoneal injection of either $(-)$ cocaine $\mathrm{HCl}(15 \mathrm{mg} / \mathrm{kg})$ or the same volume of saline per day for $5 \mathrm{~d}$. Some rats were injected within the home cage. Others were injected within the behavioral box $(16 \times 16 \times 12$ inches; Accuscan), and the locomotor responses were recorded subsequently for $15 \mathrm{~min}$. For the treatment paired with novel environment (Fig. $1 E$ ), we made a special cage with the same size as the home cage, walled with white plastic plate, floored with white-diamond soft bedding, and filled with red balls, green plastic bones, a yellow wood basin, and a wood ladder. Immediately after the injection of saline or cocaine, the rat was placed in this cage for $15 \mathrm{~min}$ and then put back into the home cage. These intraperitoneal cocaine procedures were followed by a withdrawal period of either 2 or $21 \mathrm{~d}$, during which rats were kept within the home cages. On the last withdrawal day, some rats received a challenge injection of cocaine $(12 \mathrm{mg} / \mathrm{kg})$, followed by measurement of the locomotor response. Brain slices were prepared $1 \mathrm{~h}$ later for electrophysiological recordings.

Self-administration procedure. The rats at an age of $24-28 \mathrm{~d}$ were anesthetized with the mixture of ketamine, xylazine, and acepromazine $(0.1$ $\mathrm{ml} / 100 \mathrm{mg}$ ) before surgery. A Silastic catheter was inserted into the right auricle through the external jugular vein, passed under the skin, and fixed in the midscapular region. The rats recovered from surgery for $>2 \mathrm{~d}$ before beginning self-administration training sessions. During this time, catheters were flushed every $24 \mathrm{~h}$ with sterile $0.9 \%$ saline. Experiments were conducted in operant-conditioning chambers enclosed within sound-attenuating cabinets (Med Associates). Each chamber contained an active and an inactive nose-poke hole, a food dispenser, a light used as the conditioned stimulus (CS), and a housing light. Correct nose pokes resulted in cocaine infusion $(0.75 \mathrm{mg} / \mathrm{kg}$ in $0.10 \mathrm{ml}$ over $6 \mathrm{~s})$ and illumination of a CS light inside the nose poke hole. The CS light remained on for $6 \mathrm{~s}$, whereas a house light was illuminated for $20 \mathrm{~s}$ during which active nose pokes were counted but resulted in no additional cocaine infusions. After this $20 \mathrm{~s}$ period, the house light was extinguished, and the next active nose poke resulted in a cocaine infusion. Nose pokes in the inactive hole had no reinforcement effects but were recorded. No food and water were provided in the chambers during the $2 \mathrm{~h}$ sessions.

Rats were allowed to self-administer cocaine or saline $2 \mathrm{~h} / \mathrm{d}$ for $5 \mathrm{~d}$. This relatively short-term procedure with relatively short exposure time each day was used to match the treatment duration and daily dose of the intraperitoneal injection procedure; the potential caveats related to the treatment duration and dosing could thus be minimized. The rats were then returned to the home cages for a $2 \mathrm{~d}$ or 3 week withdrawal. One day after the last withdrawal day, rats were brought back to the behavioral chambers for $2 \mathrm{~h}$, during which time some rats were connected to the perfusion pumps for cocaine reexposure by SA of cocaine $(0.6 \mathrm{mg} / \mathrm{kg}$ in $0.10 \mathrm{ml}$ over $6 \mathrm{~s}$ ), whereas others were not connected to the perfusion pumps. Nose pokes were recorded for all rats.

NAc slice preparation, cell selection, and electrophysiology. Detailed procedures for obtaining NAc slices can be found in our previous publications (Dong et al., 2006; Huang et al., 2008; Lee et al., 2008; Ishikawa et al., 2009). Briefly, coronal NAc slices of 250-300 $\mu \mathrm{m}$ thickness were cut such that the preparation contained the signature anatomical landmarks that delineated the NAc subregions. Slices were submerged in a recording chamber and were continuously perfused with regular oxygenated artificial CSF (126 mm NaCl, $1.6 \mathrm{~mm} \mathrm{KCl,} 1.2 \mathrm{~mm} \mathrm{NaH}_{2} \mathrm{PO}_{4}, 1.2 \mathrm{~mm} \mathrm{MgCl}_{2}$, $2.5 \mathrm{~mm} \mathrm{CaCl}_{2}, 18 \mathrm{~mm} \mathrm{NaHCO}_{3}$, and $11 \mathrm{~mm}$ glucose, 295-305 mOsm, equilibrated at $31-34^{\circ} \mathrm{C}$ with $95 \% \mathrm{O}_{2} / 5 \% \mathrm{CO}_{2}$ ).

Electrophysiological recordings were preferentially made from the MSNs located in the ventral-medial subregion of the NAcSh (Fig. 1A-C). MSNs in this subregion have been shown to be importantly implicated in a variety of addiction-related molecular, cellular, and behavioral alterations (Kelley, 2004; Dong et al., 2006; Huang et al., 2008). Although all neurons were recorded from the ventral-medial subregion of the NAcSh, the exact, or more accurate, location of each neuron within this subregion could not be definitively traced through the electrophysiological microscope and thus was not documented. Standard whole-cell record- ings were made using a MultiClamp 700B amplifier (Molecular Devices) through an electrode (2-6 M $\Omega$ ) in all electrophysiological experiments (Ishikawa et al., 2009). Current-clamp recordings were used to measure evoked action potentials, in which the resting membrane potential was normalized to $-80 \mathrm{mV}$ in acute slices. For these experiments, a $\mathrm{K}^{+}$. based internal solution was used [130 mM K-methansulfate, $10 \mathrm{~mm} \mathrm{KCl}$, 10 mm HEPES, 0.4 mm EGTA, $2.0 \mathrm{~mm} \mathrm{MgCl}_{2}, 2.5 \mathrm{~mm} \mathrm{MgATP}$, and 0.25 $\mathrm{mM} \mathrm{Na}_{3} \mathrm{GTP}, \mathrm{pH}$ 7.2-7.4 (275-285 mOsm)]. Only electrophysiologically "stable" neurons were included for data analysis. Briefly, after forming the whole-cell current-clamp configuration, the recorded cells were given $\sim 5$ min for stabilization (oscillating $<5 \mathrm{mV}$ ) of their resting membrane potentials. Cells with nonstabilized resting membrane potential were discontinued for the following recording. The resting membrane potential was then adjusted to $-80 \mathrm{mV}$ by injecting a small positive or negative current (usually $<30 \mathrm{pA}$ ). If the compensating current was $>50$ $\mathrm{pA}$, the recording of this neuron was discontinued. A current step protocol (from -200 to $+400 \mathrm{pA}$, with a $50 \mathrm{pA}$ increment; interpulse inter val, $15 \mathrm{~s}$ ) was then run for at least five runs (normally 20 runs). Right after the recording of a particular cell, the number of evoked action potentials was compared across all runs; cells with a run-up or rundown $>15 \%$ were excluded from additional analysis. Interneurons were occasionally confronted, which could readily be distinguished by their signature electrophysiological properties, such as relatively depolarized resting membrane potential (approximately $-72 \mathrm{mV}$ ), higher frequency of action potential firing during current injection, or the presence of large voltage sag at hyperpolarized potentials. These interneurons were excluded from data analysis. Thus, only MSNs with stable resting membrane potential and stable evoked action potential firing were included in the final analysis. The afterhyperpolarization potential (AHP) was sampled after the first action potential spike, usually elicited by the rheobase current. The input resistance was separately measured at both depolarized and hyperpolarized potentials. The measurement was taken between the injection currents -100 and $+100 \mathrm{pA}$ to minimize the significant rectifying segments in the $I-V$ curve. All chemicals were purchased from Sigma-Aldrich.

Data acquisition, analysis, and statistics. In electrophysiological recordings, two to five cells were obtained from one rat. Numbers of cells $(n)$ and animals $(m)$ are presented as $n / m$. $n$ as the default sample size was used in all statistics. In experiments related to key conclusions, animalbased statistics were also performed. In these analyses, electrophysiological parameters of all recorded cells from a single rat were averaged, and the mean was used to represent this parameter of this rat. Thus, in animal-based statistics, $n$ stands for the number of rats. In behavioral tests, $n$ stands for the number of rats. All results are shown as mean \pm SEM. One- or two-factor repeated-measures ANOVA were used in most analyses. In these analyses, factor A was assigned for the treatments (e.g., cocaine vs saline) and factor B was assigned for current injections (nine levels, $0-400 \mathrm{pA}$ with a $50 \mathrm{pA}$ interval). The statistical results were primarily presented in the $F$ and $p$ values of the main effect of factor $A$, which was the primary research interest (the effects of different cocaine treatments on membrane excitability). Degrees of freedom of between (b) and within ( $\mathrm{w}$ ) treatments were presented as $F_{(\mathrm{b}, \mathrm{w})}$. For results with factor A containing more than two levels, a least significant difference (LSD) post hoc test was performed when significance was obtained.

Computational model of NAc neuron. The computational model of NAcSh MSN was developed in the NEURON simulation environment (Hines and Carnevale, 1997; Carnevale and Hines, 2005). Simulations were performed on a Mac computer, and data analysis was performed using MATLAB (MathWorks). The NAc MSN model has been described previously in detail (Wolf et al., 2005). Briefly, the model MSN consisted of 189 compartments and included almost all the known intrinsic currents and synaptic inputs expressed in the MSN. Channels were distributed throughout the cell in accordance with published data when possible. Spines were not explicitly modeled but were accounted for by their contribution to membrane area (Segev and Burke, 1998). The internal calcium concentration in a thin shell just inside the cell membrane was tracked for each compartment. BK and SK currents were regulated by calcium influx via N-, P/Q-, and R-type calcium channels, whereas the 
remaining calcium currents contributed to a separate pool based on published experimental results (Vilchis et al., 2000). Explicit glutamatergic and GABAergic synapses were modeled using a modified two-state synapse. Glutamatergic synapses were placed throughout the dendrites but more distally relative to previous versions of the model (Wolf et al., 2005) to better reflect the actual distribution of glutamatergic synapses (Wilson, 1992; Gracy et al., 1999). Synaptic inputs were modeled using a modified version of the NetStim object provided in the NEURON package. Each synapse (glutamatergic or GABAergic) received an independent spike train generated by the following algorithm: first, a constant interspike interval (ISI) train was generated at the desired frequency. Each spike was then pulled anew from a Gaussian distribution centered at the original spike time. The resulting train was then randomly shifted, and this process was repeated for each of the 168 total synapses. Input was generated by using a large shift (one ISI) and a large SD (one-quarter of the ISI). The ratio of glutamatergic inputs to GABA inputs was held constant at $\sim 1: 1$ for all simulations (Blackwell et al., 2003).

We examined the relative effects of changes in SK channel and AMPAR conductance levels by simulating synaptic input at a frequency of 1300 $\mathrm{Hz}$ and uniformly altering the maximum conductance in all cell compartments. We examined the net effects of combined SK channel and AMPAR conductance levels at three different frequencies: 1200, 1300, and $1400 \mathrm{~Hz}$. Again, we uniformly altered the maximum conductance of these channels in all compartments. Firing frequency was calculated over a $1 \mathrm{~s}$ epoch after a $200 \mathrm{~ms}$ initialization period for each simulation. Modulation levels for the channels were determined empirically by matching cell output to physiological behavior.

\section{Results}

Several prevailing animal models have been used to understand cocaine-induced cellular and behavioral alterations. Despite its clear caveats, experimenter-performed intraperitoneal injection of cocaine remains the most widely used procedure and has helped identify a large number of cocaine-induced molecular and cellular changes. Meanwhile, SA of cocaine offers a higher clinical relevance, but its triggered neuronal changes are relatively less understood. Here, we compared the effects of intraperitoneal injection versus SA of cocaine on the intrinsic membrane excitability of MSNs located within the ventral-medial region of the NAcSh (Fig. 1A-C).

\section{Intraperitoneal injection}

Previous studies show that the intrinsic membrane excitability of NAcSh MSNs is decreased after short-term (1-2 d) or long-term (21 d) withdrawal from repeated intraperitoneal injections of cocaine (Dong et al., 2006; Ishikawa et al., 2009; Kourrich and Thomas, 2009), a process likely mediated by changes in a set of voltage-gated ion channels (Zhang et al., 1998, 2002; Hu et al., 2004). However, environmental cues, which play a significant role in drug-induced behavioral alterations (Badiani et al., 1995, 1999), were not paired in most of these studies. To examine the impact of contextual components, we compared the membrane excitability of NAcSh MSNs between rats receiving within-homecage injections and rats receiving novelty-associated injections (daily intraperitoneal injection for $5 \mathrm{~d}$; measured on day 7; no reexposure). The membrane excitability was assessed as the number of evoked action potentials. Our results show that repeated cocaine injections $\left(15 \mathrm{mg} \cdot \mathrm{kg}^{-1} \cdot \mathrm{d}^{-1}\right.$ for $5 \mathrm{~d}$ ) within either the home cage or novel cage decreased the membrane excitability of NAcSh MSNs to a similar degree $\left(F_{(3,330)}=3.75, p=0.016\right.$, two-factor ANOVA; $p=0.01$, saline-novel vs cocaine-novel; $p=$ 0.835 , cocaine-novel vs cocaine-home, LSD post hoc test) (Fig. $1 D, E)$. To analyze whether this conclusion also holds in the animal-based statistics, we used the means of the numbers of action potentials from all recorded cells in a rat to generate a single set of data for this rat and made comparisons between animals (same strategy was used for all following animal-based statistics). These animal-based statistics confirmed the results from the cell-based statistics $\left(F_{(3,84)}=5.37\right.$, two-factor ANOVA; $p=0.01$, saline-novel vs cocaine-novel; $p=0.62$, cocaine-novel vs cocaine-home, LSD post hoc test). Notably, saline injections (once per day for $5 \mathrm{~d}$ ), when paired with a novel environment, produced a trend toward a decrease in the membrane excitability ( $p=0.07$, LSD post hoc test) (Fig. $1 E$ ). Nonetheless, the above results suggest that the primary effect of cocaine alone is sufficient to decrease the membrane excitability of NAcSh MSNs.

A robust behavioral alteration triggered by intraperitoneal administration of cocaine is locomotor sensitization (Post and Rose, 1976). We next examined the potential alterations in the membrane excitability of NAcSh MSNs in rats experiencing a locomotor sensitization procedure $\left(15 \mathrm{mg} \cdot \mathrm{kg}^{-1} \cdot \mathrm{d}^{-1}\right.$, i.p., for $5 \mathrm{~d}$, followed by locomotor test within the behavioral boxes). This procedure produced a reliable cocaine-induced locomotor sensitization (day $\times$ treatment: day, $F_{(4,52)}=4.90, p<0.01$; treatment, $F_{(1,13)}=87.132, p<0.01$, two-factor ANOVA) (Fig. $\left.1 F\right)$. On the second day after withdrawal, cocaine- and salinepretreated rats, when placed back into the behavioral boxes without injections, exhibited basal locomotor activity similar to each other $\left(t_{(13)}=-1.829, p=0.10, t\right.$ test $)$. We observed that, similar to the cocaine procedure without contextual component (homecage cocaine), $2 \mathrm{~d}$ withdrawal from the locomotor sensitization procedure also decreased the membrane excitability of NAcSh MSNs $\left[F_{(1,108)}=9.31, p<0.01\right.$, two-factor ANOVA (Fig. 1G,H); animal-based statistics, $F_{(1,42)}=25.46, p<0.01$, two-factor ANOVA]. It has been shown that upregulation of SK-type $\mathrm{Ca}^{2+}$ activated potassium channels is one of the key ionic bases for the cocaine-induced decrease in membrane excitability of NAcSh MSNs (Ishikawa et al., 2009). Similarly, we observed an increase in the medium $(\mathrm{m})$ component of the AHP $\left[t_{(20)}=\right.$ $-2.21, p=0.03$, $t$ test (Fig. $1 I, J)]$ but not the fast (f) AHP $\left[t_{(20)}=0.63, p=0.53, t\right.$ test $($ Fig. $\left.1 I, J)\right]$ after short-term withdrawal from intraperitoneal injections of cocaine, suggesting a selective upregulation of the underlying SK channels. In addition to the AHP, the rheobase, the minimal current that elicits action potential, was increased in cocaine-pretreated rats, suggesting that other types of ion channels were also involved in the effect of cocaine on membrane excitability (Table 1). One such candidate is voltage-gated sodium current, which has been shown to be decreased by a similar cocaine procedure (Zhang et al., 1998). Notably, the decreased sodium current appears to be mediated by a right shift of the voltage-dependent activation (Zhang et al., 1998) and thus should not affect the basal input resistance, a change of which was not detected in the current study (Table 1).

The above results suggest that the cocaine procedure that produces locomotor sensitization decreases the membrane excitability of NAcSh MSNs. Conversely, it has been shown that experimentally decreasing the membrane excitability of NAcSh MSNs increases cocaine-induced acute locomotor responses (Dong et al., 2006). To further examine the correlation between the membrane excitability of NAcSh MSNs and cocaine-induced locomotor alteration, we included two lines of Long-Evans rats, which, referred to as the high line and low line rats, exhibit a higher and lower cocaine-induced locomotor response, respectively ( $\mathrm{Mu}$ et al., 2009). In the present study, the membrane excitability of NAcSh MSNs was substantially lower in the high line rats than in the low line rats $\left(F_{(1,114)}=6.61, p=0.02\right.$, two-factor ANOVA) (Fig. $1 K$ ). Consistent with the previous study (Mu et al., 2009), 
Table 1. Membrane properties: $2 \mathrm{~d}$ withdrawal from intraperitoneal and SA cocaine administration

\begin{tabular}{llccc}
\hline Treatment & Saline i.p. & Cocaine i.p. & Saline SA & Cocaine SA \\
\hline Number of cells & $n=9$ & $n=11$ & $n=8$ & $n=13$ \\
Break-in RMP $(\mathrm{mV})$ & $-78.0 \pm 1.3$ & $-76.6 \pm 2.4$ & $-78.3 \pm 1.0$ & $-74.0 \pm 0.9^{* *}$ \\
Stabilized RMP $(\mathrm{mV})$ & $-82.6 \pm 0.4$ & $-83.5 \pm 0.9$ & $-83.2 \pm 1.0$ & $-81.3 \pm 0.7$ \\
$R_{\mathrm{i}}$ at $-100 \mathrm{pA}(\mathrm{M} \Omega)$ & $130.4 \pm 6.0$ & $110.1 \pm 4.2$ & $133.0 \pm 4.1$ & $116.6 \pm 3.6$ \\
$R_{\mathrm{i}}$ at $+100 \mathrm{pA}(\mathrm{M} \Omega)$ & $220.7 \pm 4.4$ & $189.5 \pm 3.2$ & $212.1 \pm 2.4$ & $18.4 \pm 16$ \\
Latency, $1 \mathrm{st}$ spike $(\mathrm{ms})$ & $173 \pm 11$ & $167 \pm 31$ & $115 \pm 13(n=6)$ & $177 \pm 9.8$ \\
Rheobase $(\mathrm{pA})$ & $111 \pm 11(n=7)$ & $160 \pm 12(n=6)^{* *}$ & $-33.4 \pm 0.9$ & $164 \pm 6(n=7)^{* *}$ \\
AP threshold $(\mathrm{mV})$ & $-33.9 \pm 2.9$ & $-33.8 \pm 2.1$ & $-33.2 \pm 0.7$ \\
\hline
\end{tabular}

RMP, Resting membrane potential; $R_{\mathrm{i}}$, input resistance; AP, action potential; Rheobase, minimal current that elicits an action potential along the duration (300 ms) of the test step. ${ }^{* *} p<0.01$.
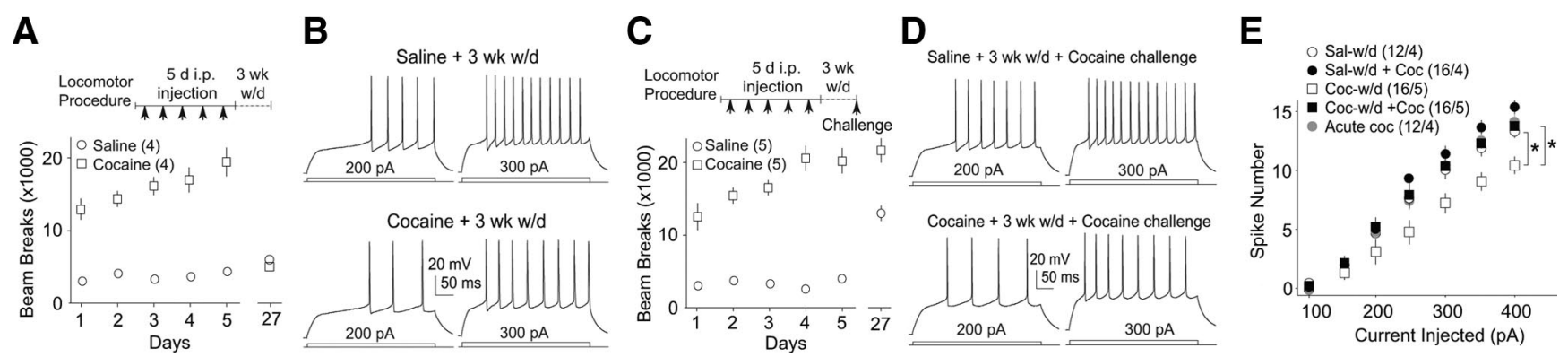

Figure 2. The intrinsic membrane excitability of NACSh MSNs was decreased in rats after 3 week withdrawal from 5 d intraperitoneal cocaine injections but returned to the baseline level after a reexposure to cocaine. $\boldsymbol{A}$, Summarized data showing the long-term withdrawal procedure (5 d intraperitoneal injection with 3 week withdrawal) and locomotor activities induced by this procedure. $\boldsymbol{B}$, Evoked action potentials in two NACSh MSNs from a saline-pretreated and a cocaine-pretreated rat in $\boldsymbol{A}$. $\boldsymbol{C}$, Summarized data showing the reexposure procedure ( $5 \mathrm{~d}$ intraperitoneal injection with 3 week withdrawal and a challenge injection) and the locomotor activities induced by this procedure. $\boldsymbol{D}$, Evoked action potentials in two NACSh MSNs from a saline-pretreated and a cocaine-pretreated rat in $\boldsymbol{C}$. $\boldsymbol{E}$, Summarized data showing that the intrinsic membrane excitability of NAcSh MSNs was decreased at the 3 week withdrawal time point after cocaine treatment but returned to the normal level (as in saline-pretreated rats) by a single challenge injection of cocaine. ${ }^{*} p<0.05$.

the cocaine-induced, but not spontaneous (Fig. $1 \mathrm{~L}$ ), locomotor responses were significantly higher in the high line rats (treatment, $F_{(1,10)}=4.98, p=0.04$, two-factor ANOVA) (Fig. $\left.1 M\right)$. To further explore the behavioral correlates of membrane excitability of NAcSh MSNs, we tested the potential differential acquisition of cocaine SA in the high and low lines rats. During the $5 \mathrm{~d}$ training period and on the challenge day (day 7; $2 \mathrm{~d}$ withdrawal), high line rats self-administered more cocaine than low line rats $\left(\right.$ animals, $F_{(1,10)}=5.41, p=0.04$, two-factor ANOVA) (Fig. $\left.1 N\right)$. Accompanying this, high line rats made fewer inactive nose pokes $\left(F_{(1,11)}=4.91, p=0.05\right.$, two-factor ANOVA) (Fig. 1O). Together, our results with high/low line rats suggest a correlation between decreased membrane excitability of NAcSh MSNs and increased cocaine-induced behavioral responses.

We then measured the membrane excitability of NAcSh MSNs after long-term withdrawal from the sensitization procedure. Rats received intraperitoneal cocaine injections for $5 \mathrm{~d}$. At $\mathrm{d}$ 5 of the treatment, rats receiving cocaine injections exhibited a clear locomotor sensitization (day, $F_{(4,24)}=3.13, p=0.03$; treatment, $F_{(1,6)}=134.45, p<0.01$ ) (Fig. $2 A$ ). Rats were then placed back into the home cages for a 3 week withdrawal. By the end of the withdrawal, the baseline locomotor activities of these rats were measured, which were not different from saline-pretreated rats $\left(t_{(6)}=-0.992, p=0.36, t\right.$ test) (Fig. $\left.2 A\right)$. The subsequent electrophysiological recordings showed that the membrane excitability of NAcSh MSNs remained low in cocaine-pretreated rats compared with saline-pretreated rats at this withdrawal time point $\left[F_{(4,384)}=2.85, p=0.031\right.$, two-factor ANOVA; $p=0.02$, saline w/d vs cocaine w/d, LSD post hoc test (Fig. $2 B, E$ ); animalbased statistics, $F_{(4,102)}=3.75, p=0.02$, two-factor ANOVA; $p=$ 0.01 , saline w/d vs cocaine w/d, LSD post hoc test]. This result is consistent with the previously observed effect of cocaine on membrane excitability of NAcSh MSNs using a procedure with- out a contextual component (Ishikawa et al., 2009). Note that the rats with the long-term withdrawal procedure were $\sim 3$ weeks older than the rats with short-term withdrawal, and the potential age-dependent regulation may contribute to the observed lower basal membrane excitability (Ishikawa et al., 2009).

We next tested whether the membrane excitability of NAcSh MSNs was affected by reexposure to cocaine after long-term withdrawal. For rats with the $5 \mathrm{~d}$ sensitization procedure and 3 week withdrawal, a challenge injection of cocaine $(12 \mathrm{mg} / \mathrm{kg})$ was given on withdrawal day 21 to verify cocaine-induced locomotor sensitization (day, $F_{(4,32)}=11.203, p<0.01$; treatment, $F_{(1,8)}=$ 97.37, $p<0.001$, two-factor ANOVA) (Fig. $2 C$ ). Then, $\sim 1$ h after the injection, electrophysiological recordings were performed. In rats reexposed to cocaine, the membrane excitability of NAcSh MSNs returned to the baseline level $\left[F_{(4,384)}=2.85, p=0.031\right.$, two-factor ANOVA; $p=0.85$, saline w/d vs saline w/d + cocaine; $p=0.01$, cocaine $\mathrm{w} / \mathrm{d}$ vs cocaine $\mathrm{w} / \mathrm{d}+$ cocaine, $\mathrm{LSD}$ post hoc test (Fig. 2D); animal-based statistics, $F_{(4,102)}=3.75, p=0.02$, twofactor ANOVA; $p=0.76$, saline $\mathrm{w} / \mathrm{d}$ vs saline $\mathrm{w} / \mathrm{d}+$ cocaine; $p=$ 0.005 , cocaine w/d vs cocaine withdrawal + cocaine, LSD post hoc test]. Notably, one injection of cocaine in the saline-pretreated rats produced a trend toward an increase in the membrane excitability of NAcSh MSNs $[p=0.07$, saline w/d vs acute cocaine, LSD post hoc test (Fig. $2 D, E) ; p=0.14$, saline w/d vs acute cocaine, LSD post hoc test, animal-based statistics], raising the possibility that the reexposure-induced increase in membrane excitability may be an acute effect of cocaine. In addition, no difference in either the fAHP $\left(t_{(25)}=-0.19, p=0.85, t\right.$ test $)$ or $\operatorname{mAHP}\left(t_{(25)}=-1.67, p=0.11, t\right.$ test $)$ in NAcSh MSNs was observed between saline- and cocaine-pretreated rats. In contrast to rats with short-term withdrawal, the rheobase was not significantly affected (Table 2), suggesting that a different set of ion 
Table 2. Membrane properties: 3 week withdrawal from intraperitoneal administration

\begin{tabular}{|c|c|c|c|c|c|}
\hline Treatment & Saline w/d & Cocaine w/d & Saline $w / d+$ cocaine & Cocaine $w / d+$ cocaine & Acute cocaine \\
\hline Number of cells & $n=12$ & $n=16$ & $n=16$ & $n=16$ & $n=12$ \\
\hline Break-in RMP (mV) & $-73.52 \pm 0.8$ & $-74.5 \pm 0.7$ & $-76.3 \pm 0.5^{*}$ & $-77.9 \pm 0.8^{* *}$ & $-75.3 \pm 0.7$ \\
\hline Stabilized RMP (mV) & $-81.3 \pm 0.7$ & $-81.1 \pm 0.5$ & $-83.2 \pm 0.6$ & $-83.3 \pm 0.6$ & $-81.1 \pm 0.9$ \\
\hline$R_{\mathrm{i}}$ at $-100 \mathrm{pA}(\mathrm{M} \Omega)$ & $137.6 \pm 7.5$ & $111.9 \pm 5.1$ & $101.8 \pm 3.0$ & $128.0 \pm 2.5$ & $103.1 \pm 3.6$ \\
\hline$R_{\mathrm{i}}$ at $+100 \mathrm{pA}(\mathrm{M} \Omega)$ & $236.4 \pm 5.3$ & $211.7 \pm 9.7$ & $233.6 \pm 6.6$ & $249.3 \pm 7.6$ & $218.9 \pm 8.1$ \\
\hline Latency, 1st spike (ms) & $188 \pm 27$ & $182 \pm 34$ & $174 \pm 14$ & $176 \pm 14$ & $171 \pm 12$ \\
\hline Rheobase (pA) & $120 \pm 15(n=5)$ & $142 \pm 11(n=8)$ & $118 \pm 10 \quad(n=6)$ & $118 \pm 16 \quad(n=7)$ & $137 \pm 7 \quad(n=4)$ \\
\hline AP threshold (mV) & $-31.3 \pm 0.9$ & $-32.2 \pm 1.2$ & $-32.3 \pm 0.5$ & $-31.8 \pm 0.9$ & $-30.9 \pm 0.6$ \\
\hline
\end{tabular}

RMP, Resting membrane potential; $R_{\mathrm{i}}$, input resistance; AP, action potential; Rheobase, minimal current that elicits an action potential along the duration ( $\left.300 \mathrm{~ms}\right)$ of the test step. RMP (mV): ${ }^{*} p<0.05$, saline w/d i.p. vs saline w/d i.p. + cocaine i.p.; ${ }^{* *} p<0.05$, cocaine w/d i.p./cocaine w/d + cocaine i.p.

channels is involved in the effect of longterm withdrawal from intraperitoneal cocaine administration.

\section{Self-administration of cocaine}

We used an SA procedure $(0.75 \mathrm{mg} / \mathrm{kg}$ per $0.1 \mathrm{ml} / 6 \mathrm{~s}$ for $2 \mathrm{~h}$ ), in which rats established a reliable SA of cocaine over a $5 \mathrm{~d}$ training period with a total cocaine intake comparable with the daily dose from the intraperitoneal procedure (day, $F_{(4,32)}=$ 7.84, $p=0.02$; treatment, $F_{(1,8)}=80.12$, $p<0.001$, two-factor ANOVA) (Fig. 3A). After $2 \mathrm{~d}$ withdrawal, rats were placed back into the SA boxes for a $2 \mathrm{~h}$ session without any cocaine treatment (Fig. 3A). The membrane excitability of NAcSh MSNs was decreased in this group of rats $\left[F_{(1,114)}=5.30, p<0.05\right.$, two-factor ANOVA (Fig. $3 B, C$ ); animal-based statistics, $F_{(1,42)}=11.21, p<0.05$, two-factor ANOVA). Similar to that produced by the intraperitoneal cocaine procedure, the mAHP in NAcSh MSNs was selectively increased in rats after $2 \mathrm{~d}$ withdrawal from cocaine SA (mAHP, $t_{(20)}=-2.73, p=$ 0.01 ; fAHP, $t_{(20)}=-1.80, p=0.08, t$ test $)$ (Fig. $3 D, E$ ). Moreover, when the rats with the $2 \mathrm{~d}$ withdrawal from the sensitization procedure and rats with the $2 \mathrm{~d}$ withdrawal from SA procedure were compared, no difference was observed in the membrane excitability of NAcSh MSNs $\left(F_{(3,222)}=8.11, p<0.01\right.$, two-factor ANOVA; $p>0.05$, intraperitoneal vs intravenous cocaine, LSD post hoc test).

To evaluate the potential environmental contribution, we ran another group of rats, which were not placed back into the behavioral boxes on day 2 of withdrawal after the $5 \mathrm{~d}$ SA procedure (without reexposure to the SA box). We observed that the membrane excitability of NAcSh MSNs was also decreased in cocainepretreated rats $\left(F_{(1,96)}=6.01, p<0.05\right.$, two-factor ANOVA) (Fig. $3 F$ ), and no difference in membrane excitability of NAcSh MSNs was observed between cocaine-pretreated rats with and without reexposure to the SA boxes $\left(F_{(3,222)}=5.67, p<0.01\right.$, two-factor ANOVA; $p=0.68$, cocaine vs cocaine with SA-box pairing; $p=0.88$, saline vs saline with the last day pairing, LSD post hoc test).

We then examined the effect of long-term withdrawal from the SA procedure. After acquiring stable SA over a $5 \mathrm{~d}$ period of training (day, $F_{(4,32)}=7.89, p<0.01$; treatment, $F_{(1,8)}=20.51$, $p<0.01$, two-factor ANOVA) (Fig. $4 A$ ), rats were returned to the home cages for a 3 week withdrawal. By the end of withdrawal, rats were placed back to the SA boxes for $2 \mathrm{~h}$ without being connected to the cocaine infusion pump. Immediately after this context exposure, rats were killed for electrophysiological recordings. Our results showed that there was no significant difference in the membrane excitability of NAcSh MSNs between salineand cocaine-pretreated rats $\left[F_{(4,402)}=3.85, p=0.01\right.$, two-factor ANOVA; $p=0.26$, saline vs cocaine w/d, LSD post hoc test (Fig. $4 B, E)$; animal-based statistics, $F_{(4,114)}=3.25, p=0.03$, twofactor ANOVA; $p=0.26$, saline w/d vs cocaine w/d, LSD post hoc test]. Thus, the membrane excitability of NAcSh MSNs becomes seemingly "normal" after the long-term withdrawal from cocaine SA.

To examine the effect of reexposure to cocaine after long-term withdrawal, we trained rats with the $5 \mathrm{~d}$ SA procedure (day, $F_{(4,40)}=$ $4.429, p<0.01$; treatment, $F_{(1,10)}=33.729, p<0.001$, two-factor ANOVA) (Fig. 4C), followed by a 3 week withdrawal. On the last day of withdrawal, we placed the rats back into the SA boxes for a $2 \mathrm{~h}$ session of cocaine SA. Thus, the reexposure is "contingent." Immediately after this behavioral procedure, brain slices were prepared for electrophysiological recordings. We observed that 



B
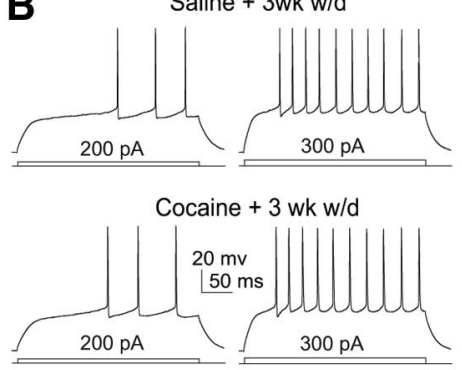

$\mathbf{F}$

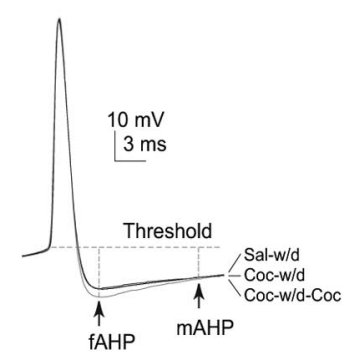

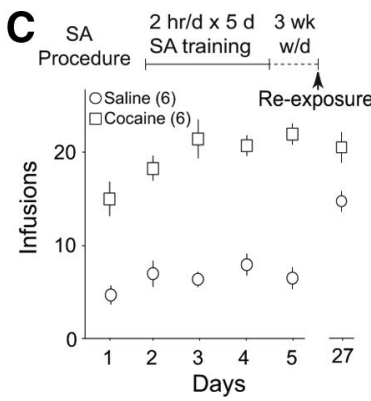

G





H

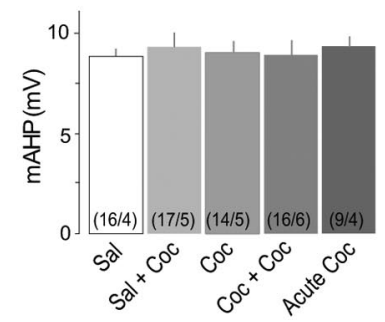

Figure 4. The intrinsic membrane excitability of NACSh MSNs returned to the baseline level after 3 week withdrawal from cocaine SA and was increased by a reexposure to cocaine. $A$, Summarized data showing the procedure of SA with a 3 week withdrawal and the performance of the rats treated with this procedure. $\boldsymbol{B}$, Evoked action potentials in two NAcSh MSNs from a saline-pretreated and a cocaine-pretreated rat in $\boldsymbol{A}$. C, Summarized data showing the procedure of SA with 3 week withdrawal and one reexposure (top) and the performance of the rats treated with this procedure. D, Evoked action potentials from a saline-pretreated and a cocaine-pretreated rat in $\boldsymbol{C}$. $\boldsymbol{E}$, Summarized data showing that, after 3 week withdrawal, the intrinsic membrane excitability of NACSh MSNs was not different between rats with SA of saline and cocaine but was increased by a reexposure to cocaine. $\boldsymbol{F}$, The averaged AHPs of all recorded MSNs from saline-pretreated and cocaine-pretreated rats. $\boldsymbol{G}, \boldsymbol{H}$, Summarized data showing that the fAHP $(\boldsymbol{G})$, but not mAHP $(\boldsymbol{H})$, was increased by a reexposure to cocaine after 3 week withdrawal from cocaine SA. ${ }^{*} p<0.05 ;{ }^{* *} p<0.01$.

Table 3. Membrane properties: 3 week withdrawal from SA administration

\begin{tabular}{|c|c|c|c|c|c|}
\hline Treatment & Saline w/d & Cocaine w/d & Saline w/d + cocaine & Cocaine w/d + cocaine & Acute cocaine \\
\hline Number of cells & $n=16$ & $n=14$ & $n=17$ & $n=16$ & $n=9$ \\
\hline Break-in RMP (mV) & $-75.2 \pm 0.9$ & $-76.5 \pm 0.7$ & $-75.1 \pm 0.8$ & $-73.3 \pm 0.9$ & $-75.1 \pm 0.7$ \\
\hline Stabilized RMP (mV) & $-82.5 \pm 0.8$ & $-83.5 \pm 0.6$ & $-81.5 \pm 0.7$ & $-80.7 \pm 0.5$ & $-81.9 \pm 0.9$ \\
\hline$R_{\mathrm{i}}$ at $-100 \mathrm{pA}(\mathrm{M} \Omega)$ & $124.9 \pm 6.8$ & $101.1 \pm 5.7$ & $109.8 \pm 4.7$ & $129.3 \pm 4.1$ & $107.4 \pm 5.7$ \\
\hline$R_{\mathrm{i}}$ at $+100 \mathrm{pA}(\mathrm{M} \Omega)$ & $240.4 \pm 7.3$ & $227.4 \pm 8.8$ & $211.9 \pm 7.6$ & $248.2 \pm 7.1$ & $222.1 \pm 4.9$ \\
\hline Latency, 1st spike (ms) & $176 \pm 12$ & $175 \pm 16$ & $183 \pm 16$ & $186 \pm 13$ & $178 \pm 11$ \\
\hline Rheobase (pA) & $133 \pm 11(n=11)$ & $114 \pm 12(n=7)$ & $135 \pm 12(n=7)$ & $110 \pm 16(n=5)$ & $121 \pm 13(n=4)$ \\
\hline AP threshold (mV) & $-30.7 \pm 0.8$ & $-30.9 \pm 1.1$ & $-31.2 \pm 0.7$ & $-29.9 \pm 0.6$ & $-31.1 \pm 0.8$ \\
\hline
\end{tabular}

$\mathrm{RMP}$, Resting membrane potential; $R_{\mathrm{i}}$, input resistance; $\mathrm{AP}$, action potential; Rheobase, minimal current that elicits an action potential along the duration (300 ms) of the test step.

the membrane excitability of NAcSh MSNs became significantly higher than that in either saline- or cocaine-pretreated rats without reexposure. Notably, in saline-pretreated rats with the last-day training of SA cocaine, the membrane excitability of NAcSh MSNs exhibited a trend toward an increase $\left[F_{(4,402)}=3.85, p=0.01\right.$, two-factor ANOVA; $p=0.05$, saline $\mathrm{w} / \mathrm{d}$ vs saline $\mathrm{w} / \mathrm{d}+$ cocaine; $p=0.04$, cocaine $\mathrm{w} / \mathrm{d}$ vs cocaine $\mathrm{w} / \mathrm{d}+$ cocaine $; p=0.11$, saline $\mathrm{w} / \mathrm{d}$ vs acute cocaine, LSD post hoc test (Fig. $4 D, E$ ); animal-based statistics, $F_{(4,114)}=3.25$, $p=0.03$, two-factor ANOVA; $p=0.09$, saline $\mathrm{w} / \mathrm{d}$ vs saline $\mathrm{w} / \mathrm{d}+$ cocaine; $p=0.01$, cocaine $\mathrm{w} / \mathrm{d}$ vs cocaine $\mathrm{w} / \mathrm{d}+\mathrm{co}-$ caine; $p=0.18$, saline $\mathrm{w} / \mathrm{d}$ vs acute cocaine]. In contrast to the intraperitoneal procedure, a reexposure to cocaine selectively increased the fAHP $\left(F_{(4,71)}=4.88, p<0.01\right.$, one-factor ANOVA) (Fig. $4 F, G$ ) in NAcSh MSNs without affecting the $\operatorname{mAHP}\left(F_{(4,71)}=0.67, p=0.86\right.$, one-factor ANOVA) (Fig. $4 F, H)$ or other active and passive membrane properties (Table 3). As demonstrated previously, an upregulation of the BK-type $\mathrm{Ca}^{2+}$-activated potassium channel, reflected in the current-clamp recording as an increase in the fAHP, may expedite the repolarization of the membrane during action po- tential and thus increase the firing rate (Ishikawa et al., 2009). Thus, this increase in the fAHP, or BK channels, may contribute to the reexposure-induced increase in membrane excitability of NAcSh MSNs.

\section{Computational model}

Using a computational model, we made an attempt to predict cocaine-induced functional alterations of NAcSh MSNs by integrating cocaine-induced membrane and synaptic adaptations. In this model, the functional output of NAcSh MSNs was defined as the number of action potentials (spikes) driven by excitatory synaptic inputs. For cocaine-induced membrane alterations, we focused on the SK channels and defined the computational range of changes in SK channel activity based on our present (Figs. 3, 4) and previous (Ishikawa et al., 2009) results. For cocaine-induced alterations in excitatory synaptic input, we focused on AMPARbased synaptic strength and defined the computational range of changes based on published results (Boudreau and Wolf, 2005; Boudreau et al., 2007, 2009; Kourrich et al., 2007; Conrad et al., 2008). With this model, we first examined the independent effects of cocaine-induced changes in membrane properties and 



Figure 5. A computational model predicts that the functional output of NACSh MSNs is differentially regulated by different cocaine procedures, different withdrawal duration, and reexposure after long-term withdrawal from different cocaine procedures. $A$, The SK channel activity, when considered alone, was negatively and linearly correlated with the functional output (spikes) of the model NACSh MSN. Thus, this model predicts that the cocaine-induced increase in SK channel activity tends to decrease the functional output of NAcSh MSNs. Inset, Diagram of model NAcSh MSN. B, The synaptic strength (AMPAR activity), when considered alone, was positively and linearly correlated with the functional output of the model NAcSh MSNs. Thus, the model predicts that cocaine-induced increase or decrease in excitatory synaptic strength tends to increase or decrease, respectively, the functional output of NAcSh MSNs. C, D, Results showing the predicted functional outputs of the model NACSh MSN when changes in SK channel activity and excitatory synapses were integrated. The baseline excitatory synaptic strength was defined as the $1300 \mathrm{~Hz}$ frequency input. The top gray line shows the functional output (spikes) of the model MSN when integrating an increase in SK channel activity and an increase in excitatory synaptic strength (from 1300 to $1400 \mathrm{~Hz}$ ). The bottom gray line shows the functional output of the model MSN when integrating an increase in SK channel activity and a decrease in excitatory synaptic strength (from 1300 to $1200 \mathrm{~Hz}$ ). These modeling results suggest that, after intraperitoneal injection of cocaine, the overall functional output of NACSh MSNs is upregulated after short-short or long-term withdrawal but increased by reexposure to cocaine (filled arrows in $\boldsymbol{C}$ ), and, after cocaine SA, the overall functional output of NACSh MSNs is downregulated during short-term withdrawal, upregulated during long-term withdrawal, and upregulated further by reexposure to cocaine (filled arrows in $\boldsymbol{D})$.

excitatory synapses on the functional output (spikes) of NAcSh MSNs. The results show that, if acting independently, cocaine-induced upregulation of the SK channel activity decreased the spike output of NAcSh MSNs (Fig. 5A), whereas cocaine-induced upregulation of excitatory synaptic strength produced the opposite effect (Fig. 5B). Furthermore, both membrane and synapse-mediated modulations exhibited a linear relationship (Fig. 5A,B), as suggested previously (Moyer et al., 2007). We next integrated cocaine-induced alterations in both the membrane property and excitatory synaptic input in this model to predict how the overall functional output (spikes) of NAcSh MSNs was affected by different cocaine procedures at different stages of exposure/withdrawal. The baseline excitatory synaptic activity was set at $1300 \mathrm{~Hz}$, with a $100 \mathrm{~Hz}$ upregulation or downregulation. This model predicted that, after repeated intraperitoneal injections of cocaine, the overall functional output (number of spikes driven by excitatory synapses) of NAcSh MSNs was increased at both short- and longterm withdrawal time points but was decreased after reexposure to cocaine (Fig. $5 C$ ). This model also predicted that cocaine-induced alterations in excitatory synaptic inputs may override the cocaine-induced membrane alteration and predominantly regulate the output of NAcSh MSNs. Conversely, after cocaine SA, the functional output of NAcSh MSNs was decreased after short-term withdrawal (e.g., 1 d), increased after long-term withdrawal (e.g., $45 \mathrm{~d}$ ), and increased further after reexposure (Fig. 5D). Together, these modeling results suggest that the functional output of NAcSh MSNs is differentially regulated by different cocaine procedures, different withdrawal durations, and reexposures to cocaine.

\section{Discussion}

We have demonstrated that the intrinsic membrane excitability of NAcSh MSNs underwent dynamic changes after different cocaine procedures and at different stages of cocaine withdrawal. These results, combined with the knowledge on cocaine-induced synaptic alterations, may help understand the dynamic functional output of NAcSh MSNs in cocaine-induced behaviors.
Functional alterations in NAcSh MSNs after different cocaine administration procedures

In anesthetized animals, NAc MSNs dwell at two alternating states, the functionally inactive downstate at which the membrane potential is relatively hyperpolarized and MSNs are often quiescent, and the functionally active upstate at which the membrane potential is relatively depolarized and MSNs are prone to firing action potentials (O'Donnell and Grace, 1995; Wilson and Kawaguchi, 1996). Both in vitro and in vivo studies show that the upstate is mediated by synchronous activation of excitatory synapses (O'Donnell and Grace, 1995; Plenz and Kitai, 1996; Plenz et al., 1998). In behaving animals, NAc MSNs likely spend most of their time in the upstate, presumably as a result of continuous excitatory inputs (Mahon et al., 2006). Nonetheless, it is excitatory synaptic input that depolarizes the membrane potential toward the action potential threshold, and it is the intrinsic membrane excitability that sets the action potential threshold and determines how often to fire action potentials once MSNs dwell at the threshold. Thus, the functional output of NAc MSNs critically relies on the integration of both excitatory synaptic input and membrane excitability.

After intraperitoneal cocaine injection-induced locomotor sensitization, the strength of excitatory synapses at NAcSh MSNs is increased after 7-21 d of withdrawal and decreased $24 \mathrm{~h}$ after reexposure following withdrawal (Boudreau and Wolf, 2005; Boudreau et al., 2007; Kourrich et al., 2007; Ferrario et al., 2010). Our current results show that the membrane excitability of NAcSh MSNs was decreased at both short and long withdrawal time points and returned to the normal level on $\sim 1 \mathrm{~h}$ after cocaine reexposure (Fig. 1). Together with previous results (Zhang et al., 1998, 2002; Hu et al., 2004), our present findings suggest that cocaine-induced alterations in excitatory synapses and membrane excitability of NAcSh MSNs may partially cancel out each other's effects at the functional output level. Homeostatic synapse-driven membrane plasticity (hSMP) was recently defined in NAcSh MSNs, through which the membrane excitability can be adjusted to functionally compensate for the changes in excitatory synapses (Ishikawa et al., 2009). This hSMP may be 
one of the mechanisms that coordinate excitatory synapses and membrane excitability of NAcSh MSNs after the intraperitoneal injection procedure. Furthermore, although the role of NAc excitatory synapses in cocaine-induced locomotor sensitization has long been established (Wolf, 1998), our results suggest that it is more likely that the overall functional output, i.e., the integration of excitatory synaptic input and the membrane excitability as well as other components, sets up the sensitized psychomotor state. The role of membrane excitability of NAcSh MSNs in cocaineinduced locomotor sensitization is emerging; a recent study shows that experimentally decreasing the membrane excitability of in vivo NAcSh MSNs by overexpressing potassium channels increases the acute effect of cocaine on locomotor responses (Dong et al., 2006). Consistent with this notion, our current study using a repeated cocaine procedure in high line and low line rats show that the decreased membrane excitability of NAcSh MSNs is correlative to cocaine-elicited locomotor sensitization (Fig. $1 K-M$ ). Furthermore, the differential acquisition patterns of cocaine SA in high line and low line rats (Fig. $1 \mathrm{~N}, \mathrm{O}$ ) suggest that the membrane excitability of NAcSh MSNs is involved in not only the locomotor response but likely a large repertoire of cocaine-related behaviors.

After the procedure of cocaine SA, the strength of excitatory synapses at NAcSh MSNs is increased after long-term withdrawal (Conrad et al., 2008). Whereas the change of excitatory synaptic strength after reexposure has not been comprehensively examined, one study suggests that the function of synaptic AMPARs may be upregulated (Anderson et al., 2008). In the present study, the membrane excitability of NAcSh MSNs was decreased after short-term withdrawal but returned to normal levels after longterm withdrawal and was increased after reexposure to cocaine (Figs. 3, 4). Thus, the net effect of cocaine on excitatory synapses and membrane excitability would be to increase the overall activation level of NAc MSNs after long-term withdrawal from cocaine SA (Fig. 5D).

Together, our results demonstrate that the intrinsic membrane excitability of NAcSh MSNs changes after different procedures of cocaine exposure and over different stages of withdrawal; these changes are temporally correlated with the synaptic alterations, which seem to be functionally opposite at certain withdrawal time points. Although some of the cooccurring, functionally counteracting changes across the subcellular domains appear to help maintain the stability of NAcSh MSNs on the overall functional level, it is likely that the functional output of NAcSh MSNs is still skewed during certain working range (Fig. 5C,D).

\section{Interpretational limitations}

Focusing on two key components of the basic neuronal machinery, the above discussion together with the modeling results (Fig. 5) should provide a comprehensive understanding about how NAcSh MSNs respond to excitatory inputs after short- and long-term withdrawal following cocaine administration. Two key potential caveats should be noted in these modeling results. First, the membrane excitability and excitatory synaptic strength after short- and long-term withdrawal were approximated based on our current results and published results (Boudreau and Wolf, 2005; Boudreau et al., 2007; Kourrich et al., 2007; Conrad et al., 2008; Ferrario et al., 2010; Ishikawa et al., 2009). In these studies, the exact time points of withdrawal as well as the time points at which the biochemical and electrophysiological measurements of membrane excitability and excitatory synapses were performed were not always precisely matched. For example, for reexposure after long-term withdrawal from cocaine SA (Fig. 5D), the data of membrane excitability included in the model were collected at $1 \mathrm{~h}$ after reexposure (current results), whereas the data about excitatory synaptic strength were collected at $\sim 30$ min (Anderson et al., 2008). These imperfectly matched measurement time points may cause inaccurate estimations. Second, although a number of ionic conductances (e.g., $\mathrm{Na}^{+}, \mathrm{K}^{+}$, and $\mathrm{Ca}^{2+}$ currents) are likely involved in cocaine-induced membrane adaptation (Zhang et al., 1998, 2002; $\mathrm{Hu}$ et al., 2004), the related data are not available at each key time point. We thus included only SK channel-related data (Ishikawa et al., 2009) in the modeling work. This simplification may in part account for the lower impact of membrane excitability on the overall functional output of NAcSh MSNs predicted by the model (Fig. $5 A, B$ ).

Moreover, to assess the real-time activity of these neurons in vivo, factors within the circuitry must also be considered. First, presynaptic inputs are the driving force to depolarize or hyperpolarize the membrane potential of NAcSh MSNs (Wilson, 1986; Plenz and Kitai, 1998). Presynaptic excitatory and inhibitory inputs, as well as their temporal integration, are the potential target of cocaine exposure (Shoji et al., 1997; Kozell and Meshul, 2004), and the resulting changes may substantially change the duration/frequency of the upstates of NAcSh MSNs. Second, the observations of increased dendritic spine density (Robinson and Kolb, 1997; Kolb et al., 2003) and potentially new synaptic connections (Huang et al., 2009) after cocaine exposure raise the possibility that new input pathways may be generated. If so, these potential new pathways may process qualitatively distinct information that cannot be quantitatively evaluated as an increase or decrease in synaptic strength. Third, a number of neuromodulators, such as dopamine, serotonin, norepinephrine, and neurotrophins, constitutively regulate both the membrane and synaptic properties of NAcSh MSNs (Koob and Nestler, 1997). During cocaine exposure, these neuromodulator/neurotrophin systems also undergo adaptive and dynamic changes (Koob and Nestler, 1997), which, in turn, may reshape the realtime functional output of these neurons. Nonetheless, with these interpretational caveats, predictions of the functional output of NAcSh MSNs based on the above analyses are essentially consistent with some of the neuroimaging studies that directly measure the activation level of the NAc during cocaine exposure. For example, in intraperitoneal cocaine-pretreated rats, a reexposure to cocaine slightly increases the activity level of the NAc, with an effect much less than acute cocaine exposure in naive rats (Febo et al., 2005), whereas in human subjects who previously "self-administer" cocaine, a reexposure to cocaine substantially increases the activity level of the NAc (Breiter et al., 1997).

In summary, the current study provides essential information to assess the overall functional alterations of NAcSh MSNs by cocaine exposure. Analyses based on the current results along with previous results (Boudreau and Wolf, 2005; Boudreau et al., 2007; Kourrich et al., 2007) support the hypothesis that NAc MSNs act dynamically during different stages of cocaine exposure and withdrawal. These results shed light on the path toward understanding the cellular and molecular bases underlying drug-induced emotional and motivational alterations, such as drug-craving and drugwithdrawal-induced depression. 


\section{References}

Anderson SM, Famous KR, Sadri-Vakili G, Kumaresan V, Schmidt HD, Bass CE, Terwilliger EF, Cha JH, Pierce RC (2008) CaMKII: a biochemical bridge linking accumbens dopamine and glutamate systems in cocaine seeking. Nat Neurosci 11:344-353.

Badiani A, Anagnostaras SG, Robinson TE (1995) The development of sensitization to the psychomotor stimulant effects of amphetamine is enhanced in a novel environment. Psychopharmacology (Berl) 117:443452.

Badiani A, Oates MM, Day HE, Watson SJ, Akil H, Robinson TE (1999) Environmental modulation of amphetamine-induced c-fos expression in D1 versus D2 striatal neurons. Behav Brain Res 103:203-209.

Blackwell KT, Czubayko U, Plenz D (2003) Quantitative estimate of synaptic inputs to striatal neurons during up and down states in vitro. J Neurosci 23:9123-9132.

Boudreau AC, Wolf ME (2005) Behavioral sensitization to cocaine is associated with increased AMPA receptor surface expression in the nucleus accumbens. J Neurosci 25:9144-9151.

Boudreau AC, Reimers JM, Milovanovic M, Wolf ME (2007) Cell surface AMPA receptors in the rat nucleus accumbens increase during cocaine withdrawal but internalize after cocaine challenge in association with altered activation of mitogen-activated protein kinases. J Neurosci 27:10621-10635.

Boudreau AC, Ferrario CR, Glucksman MJ, Wolf ME (2009) Signaling pathway adaptations and novel protein kinase A substrates related to behavioral sensitization to cocaine. J Neurochem 110:363-377.

Breiter HC, Gollub RL, Weisskoff RM, Kennedy DN, Makris N, Berke JD, Goodman JM, Kantor HL, Gastfriend DR, Riorden JP, Mathew RT, Rosen BR, Hyman SE (1997) Acute effects of cocaine on human brain activity and emotion. Neuron 19:591-611.

Burgdorf J, Panksepp J, Brudzynski SM, Kroes R, Moskal JR (2005) Breeding for $50-\mathrm{kHz}$ positive affective vocalization in rats. Behav Genet 35:67-72.

Carnevale NT, Hines ML (2005) The NEURON book. Cambridge, UK: Cambridge UP.

Conrad KL, Tseng KY, Uejima JL, Reimers JM, Heng LJ, Shaham Y, Marinelli M, Wolf ME (2008) Formation of accumbens GluR2-lacking AMPA receptors mediates incubation of cocaine craving. Nature 454:118-121.

Dong Y, Nasif FJ, Tsui JJ, Ju WY, Cooper DC, Hu XT, Malenka RC, White FJ (2005) Cocaine-induced plasticity of intrinsic membrane properties in prefrontal cortex pyramidal neurons: adaptations in potassium currents. J Neurosci 25:936-940.

Dong Y, Green T, Saal D, Marie H, Neve R, Nestler EJ, Malenka RC (2006) CREB modulates excitability of nucleus accumbens neurons. Nat Neurosci 9:475-477.

Febo M, Segarra AC, Nair G, Schmidt K, Duong TQ, Ferris CF (2005) The neural consequences of repeated cocaine exposure revealed by functional MRI in awake rats. Neuropsychopharmacology 30:936-943.

Ferrario CR, Li X, Wang X, Reimers JM, Uejima JL, WolfME (2010) The role of glutamate receptor redistribution in locomotor sensitization to cocaine. Neuropsychopharmacology 35:818-833.

Gracy KN, Clarke CL, Meyers MB, Pickel VM (1999) N-methyl-D-aspartate receptor 1 in the caudate-putamen nucleus: ultrastructural localization and co-expression with sorcin, a 22,000 mol. wt calcium binding protein. Neuroscience 90:107-117.

Henry DJ, White FJ (1992) Electrophysiological correlates of psychomotor stimulant-induced sensitization. Ann N Y Acad Sci 654:88-100.

Hille B (2001) Ion channels of excitable membrane. Sunderland, MA: Sinauer.

Hines ML, Carnevale NT (1997) The NEURON simulation environment. Neural Comput 9:1179-1209.

Hu XT, Basu S, White FJ (2004) Repeated cocaine administration suppresses HVA-Ca ${ }^{2+}$ potentials and enhances activity of $\mathrm{K}^{+}$channels in rat nucleus accumbens neurons. J Neurophysiol 92:1597-1607.

Huang YH, Lin Y, Brown TE, Han MH, Saal DB, Neve RL, Zukin RS, Sorg BA, Nestler EJ, Malenka RC, Dong Y (2008) CREB modulates the functional output of nucleus accumbens neurons: a critical role of $N$-methyl-Daspartate glutamate receptor (NMDAR) receptors. J Biol Chem 283:27512760.

Huang YH, Lin Y, Mu P, Lee BR, Brown TE, Wayman G, Marie H, Liu W, Yan Z, Sorg BA, Schlüter OM, Zukin RS, Dong Y (2009) In vivo cocaine experience generates silent synapses. Neuron 63:40-47.
Hyman SE, Malenka RC, Nestler EJ (2006) Neural mechanisms of addiction: the role of reward-related learning and memory. Annu Rev Neurosci 29:565-598.

Ishikawa M, Mu P, Moyer JT, Wolf JA, Quock RM, Davies NM, Hu XT, Schlüter OM, Dong Y (2009) Homeostatic synapse-driven membrane plasticity in nucleus accumbens neurons. J Neurosci 29: $5820-5831$.

Kelley AE (2004) Ventral striatal control of appetitive motivation: role in ingestive behavior and reward-related learning. Neurosci Biobehav Rev 27:765-776.

Kolb B, Gorny G, Li Y, Samaha AN, Robinson TE (2003) Amphetamine or cocaine limits the ability of later experience to promote structural plasticity in the neocortex and nucleus accumbens. Proc Natl Acad Sci U S A 100:10523-10528.

Koob GF, Nestler EJ (1997) The neurobiology of drug addiction. J Neuropsychiatry Clin Neurosci 9:482-497.

Kourrich S, Thomas MJ (2009) Similar neurons, opposite adaptations: psychostimulant experience differentially alters firing properties in accumbens core versus shell. J Neurosci 29:12275-12283.

Kourrich S, Rothwell PE, Klug JR, Thomas MJ (2007) Cocaine experience controls bidirectional synaptic plasticity in the nucleus accumbens. J Neurosci 27:7921-7928.

Kozell LB, Meshul CK (2004) Nerve terminal glutamate immunoreactivity in the rat nucleus accumbens and ventral tegmental area after a short withdrawal from cocaine. Synapse 51:224-232.

Lee BR, Mu P, Saal DB, Ulibarri C, Dong Y (2008) Homeostatic recovery of downstate-upstate cycling in nucleus accumbens neurons. Neurosci Lett 434:282-288.

Mahon S, Vautrelle N, Pezard L, Slaght SJ, Deniau JM, Chouvet G, Charpier S (2006) Distinct patterns of striatal medium spiny neuron activity during the natural sleep-wake cycle. J Neurosci 26:12587-12595.

Moyer JT, Wolf JA, Finkel LH (2007) Effects of dopaminergic modulation on the integrative properties of the ventral striatal medium spiny neuron. J Neurophysiol 98:3731-3748.

Mu P, Fuchs T, Saal DB, Sorg BA, Dong Y, Panksepp J (2009) Repeated cocaine exposure induces sensitization of ultrasonic vocalization in rats. Neurosci Lett 453:31-35.

O'Donnell P, Grace AA (1995) Synaptic interactions among excitatory afferents to nucleus accumbens neurons: hippocampal gating of prefrontal cortical input. J Neurosci 15:3622-3639.

Panksepp J, Burgdorf J (2003) "Laughing" rats and the evolutionary antecedents of human joy? Physiol Behav 79:533-547.

Perry JL, Anderson MM, Nelson SE, Carroll ME (2007) Acquisition of i.v. cocaine self-administration in adolescent and adult male rats selectively bred for high and low saccharin intake. Physiol Behav 91:126-133.

Plenz D, Kitai ST (1996) Organotypic cortex-striatum-mesencephalon cultures: the nigrostriatal pathway. Neurosci Lett 209:177-180.

Plenz D, Kitai ST (1998) Up and down states in striatal medium spiny neurons simultaneously recorded with spontaneous activity in fast-spiking interneurons studied in cortex-striatum-substantia nigra organotypic cultures. J Neurosci 18:266-283.

Plenz D, Herrera-Marschitz M, Kitai ST (1998) Morphological organization of the globus pallidus-subthalamic nucleus system studied in organotypic cultures. J Comp Neurol 397:437-457.

Post RM, Rose H (1976) Increasing effects of repetitive cocaine administration in the rat. Nature 260:731-732.

Robinson TE, Kolb B (1997) Persistent structural modifications in nucleus accumbens and prefrontal cortex neurons produced by previous experience with amphetamine. J Neurosci 17:8491-8497.

Segev I, Burke RE (1998) Compartmental models of complex neurons. In: Methods in neuronal modeling: from ions to networks, Ed 2 (Koch C, Segev I, eds), pp 93-136. Cambridge, MA: Massachusetts Institute of Technology.

Shoji S, Simms D, McDaniel WC, Gallagher JP (1997) Chronic cocaine enhances gamma-aminobutyric acid and glutamate release by altering presynaptic and not postsynaptic gamma-aminobutyric acidB receptors within the rat dorsolateral septal nucleus. J Pharmacol Exp Ther 280:129-137.

Vilchis C, Bargas J, Ayala GX, Galván E, Galarraga E (2000) $\mathrm{Ca}^{2+}$ channels that activate $\mathrm{Ca}^{2+}$-dependent $\mathrm{K}^{+}$currents in neostriatal neurons. Neuroscience 95:745-752. 
White FJ, Kalivas PW (1998) Neuroadaptations involved in amphetamine and cocaine addiction. Drug Alcohol Depend 51:141-153.

Wilson CJ (1986) Postsynaptic potentials evoked in spiny neostriatal projection neurons by stimulation of ipsilateral and contralateral neocortex. Brain Res 367:201-213.

Wilson CJ (1992) Dendritic morphology, inward rectification, and the functional properties of neostriatal neurons. In: Single neuron computation (McKenna T, Davis J, Zornetzer S, eds), pp 141-171. San Diego: Academic.

Wilson CJ, Groves PM (1981) Spontaneous firing patterns of identified spiny neurons in the rat neostriatum. Brain Res 220:67-80.

Wilson CJ, Kawaguchi Y (1996) The origins of two-state spontaneous membrane potential fluctuations of neostriatal spiny neurons. J Neurosci 16:2397-2410.
Wolf JA, Moyer JT, Lazarewicz MT, Contreras D, Benoit-Marand M, O’Donnell P, Finkel LH (2005) NMDA/AMPA ratio impacts state transitions and entrainment to oscillations in a computational model of the nucleus accumbens medium spiny projection neuron. J Neurosci 25: 9080-9095.

Wolf ME (1998) The role of excitatory amino acids in behavioral sensitization to psychomotor stimulants. Prog Neurobiol 54:679-720.

Zhang XF, Hu XT, White FJ (1998) Whole-cell plasticity in cocaine withdrawal: reduced sodium currents in nucleus accumbens neurons. J Neurosci 18:488-498.

Zhang XF, Cooper DC, White FJ (2002) Repeated cocaine treatment decreases whole-cell calcium current in rat nucleus accumbens neurons. J Pharmacol Exp Ther 301:1119-1125. 